\title{
Correspondence
}

\section{Characterisation of human articular cartilage link proteins from normal and osteoarthritic cartilage: a comment}

SIR, Ryu et al.$^{1}$ studied the ability of human articular cartilage link proteins to stabilise the interaction between proteoglycan subunit (from bovine tracheal cartilage) and high

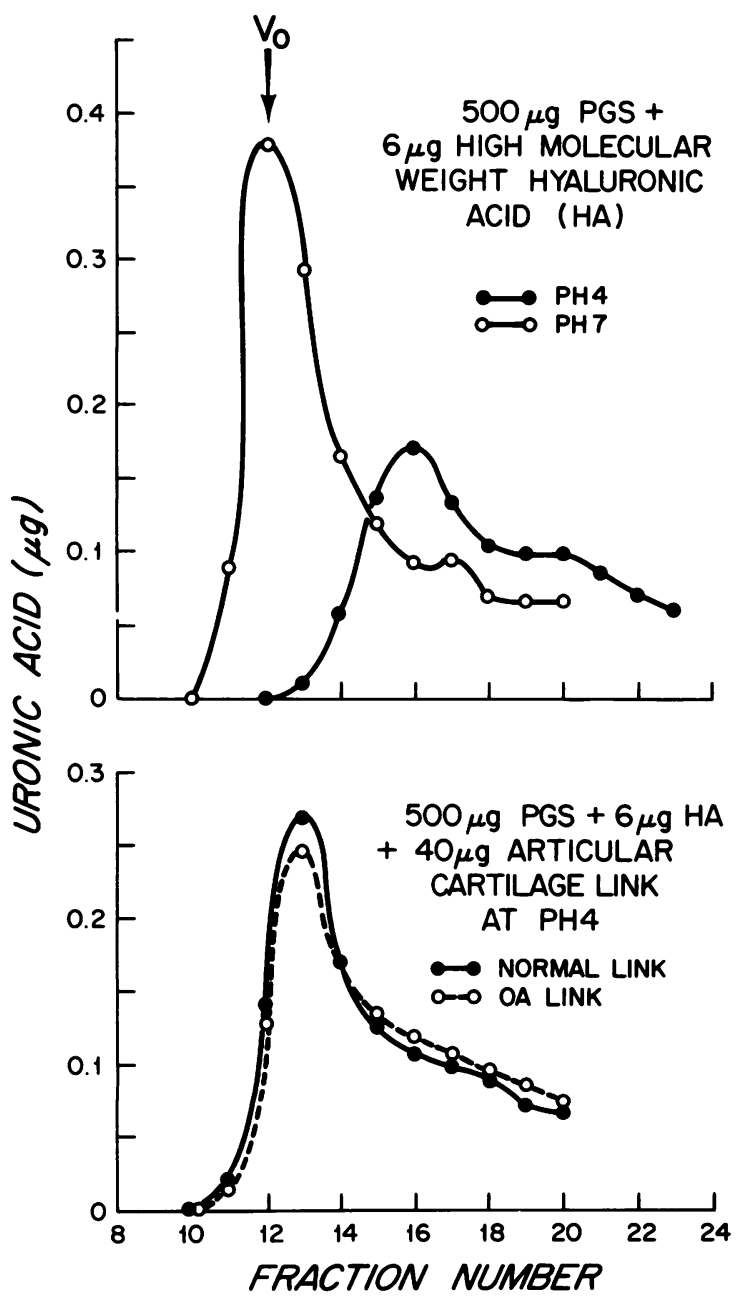

Fig. $2 C L$-Sepharose $2 B$ filtration of proteoglycan aggregates. molecular weight hyaluronate. They used Sepharose 2B gel chromatography to demonstrate the interaction, equating material eluting in the void volume of the column with aggregated material.

Their Fig. 2 reproduced below shows the gel elution profile they obtained.

When interpreting their results it is important to note the apparently low recovery of material applied to the column. The Sepharose $2 \mathrm{~B}$ column used was small $(1 \times 22 \mathrm{~cm})$ and run at a high flow rate $(18 \mathrm{ml} /$ hour $)$. The void volume $\left(\mathrm{V}_{0}\right)$ of such a column would occur in the region of $8 \mathrm{ml}$, and effectively all the material would be eluted by one column volume of eluant. Considering the major peak in the upper half of Fig. 2, fractions $10-20$ should contain the eluted uronate in under about $20 \mathrm{ml}$ of eluant. The area under this curve determined gravimetrically corresponds to approximately $2.8 \mu \mathrm{g}$ of uronate, assuming that uronate is measured in $\mu \mathrm{g} / \mathrm{ml}$, whereas around $120 \mu \mathrm{g}$ of uronate would be present in the $500 \mu \mathrm{g}$ of proteoglycan applied to the column. At $\mathrm{pH} 4$ only around $2 \mu \mathrm{g}$ of uronate appears to have been eluted. The same conclusions apply to the elution profiles in the lower half of the diagram.

I would also question the validity of equating material eluting in the void volume of a Sepharose $2 B$ column with aggregated material. I would be surprised if rechromatography of the leading half of the void volume peak did not lead to the redistribution of some material into the included volume. As far as I am aware, Sepharose 2B chromatography has not allowed the isolation and study of $100 \%$ aggregated material. This consideration clearly also bears on the interpretation of a number of other similar studies.

Department of Medicine, D. W. BULLIMORE St James's Hospital, Leeds LS9 7TF

Reference

1 Ryu J, Towle C A, Treadwell B V. Characterisation of human articular cartilage link proteins from normal and osteoarthritic cartilage. Ann Rheum Dis 1982; 41: 164-7.

SIR, Dr Bullimore is correct with his calculations on the quantity of uronic acid which we should have obtained eluting off the Sepharose 2B column. The ordinate of this graph is in error. It should read uronic acid $\left(\mu \mathrm{g} \times 10^{-2}\right)$. The fraction volumes were not $1 \mathrm{ml}$ but $0.6 \mathrm{ml}$ and the void volume of the column is approximately $7.5 \mathrm{ml}$.

I agree with Dr Bullimore's comment that 2B column chromatography does not allow one to conclude that all the uronic acid containing material eluting in the void volume is aggregate. The purpose of this article was simply to demonstrate that osteoarthritic link was effective in shifting the bulk of the proteoglycans into the void volume, presumably through stabilisation of the subunits with hyaluronic acid. 
This procedure for measuring aggregate represents a modification of methods as described. ${ }^{12}$ To my knowledge there is no method one can use to obtain pure aggregate. The classical method for obtaining aggregate employing centrifugation in caesium chloride density gradients does not yield $100 \%$ aggregate. There are nonaggregatable proteoglycans present in this fraction as well.

Dept. of Orthopaedic Surgery, BENJAMIN v. TREADWELl Massachusetts General Hospital,

Boston, Massachusetts 02114, USA

\section{References}

1 Hardingham T E. Proteoglycans from bovine nasal cartilage: properties of a soluble form of link protein. Biochem J 1979; 177: 237-47.

2 Tang L H, Rosenberg L, Reiner A, Poole A R. The role of link-protein in the structure of cartilage proteoglycan aggregates. J Biol Chem 1979; 254: 10523-31.

\section{Chromosomes in rheumatoid arthritis}

SIR, Lymphoproliferative disorders are more frequently found in patients with autoimmune disease than in normal persons. Isomaki et $a^{1}$ showed an increased risk of leukaemia, lymphoma, Hodgkin's disease, and multiple myeloma in rheumatoid arthritis (RA) patients. These investigators postulated that a continuous immunological stimulation in RA could cause proliferation and malignant transformation of the immunologically competent cell clones. Green et al. $^{2}$ believe that immunodeficiency in patients with autoimmune disease may be a factor in the development of lymphoproliferative disease.

We found marked chromosomal abnormalities in a patient with lymphoma who was treated with intraarticular radioactive gold $\left({ }^{198} \mathrm{Au}\right)$ for severe RA. ${ }^{3}$ Although we were tempted to conclude the chromosomal abnormalities found in our patient were due to her ${ }^{198} \mathrm{Au}$ treatment, we were unable to exclude the possibility that the phenylbutazone and prednisone treatments or the deveolpment of her lymphoma or RA may have been the cause of the chromosomal abnormalities. This communication reports our chromosomal findings of 21 RA patients with various treatments and of 28 controls.

Heparinised peripheral blood was obtained for cytogenetic studies from 21 active RA patients. Five patients received $10 \mathrm{mCi}$ of intra-articular ${ }^{198} \mathrm{Au} ; 14$ received intramuscular nonradioactive gold; and 2 received full therapeutic doses of aspirin $(7800 \mathrm{mg} /$ day $)$. The controls consisted of 28 hospital employees without any known illnesses. Peripheral blood was cultured in TC 199 tissue culture medium, enriched with either autologous plasma or fetal calf serum and stimulated with phytohemagglutinin (PHA) according to the method used in our laboratory. ${ }^{3}$ After incubation at $37^{\circ} \mathrm{C}$ for three days the cultures were exposed to colcemid at a concentration of
$0.16 \mu \mathrm{g} / \mathrm{ml}$ for one hour. The cells were then exposed to $0.075 \mathrm{M} \mathrm{KC1}$ for half an hour, fixed with acetoalcohol, and the slides made by the air-dried method. The slides were stained with Giemsa and analysed for chromosomal breakages as described. ${ }^{4}$

The mean rate of chromosomal breakages was $8.6 \pm$ 2.4 (SEM) in the 5 RA patients treated with ${ }^{198} \mathrm{Au} ; 9.4 \pm$ 1.43 in the 14 treated with nonradioactive gold; and 5.5 in the 2 treated with high doses of aspirin. The 28 controls had a frequency of $3.67 \pm 0.56$. The mean difference of the chromosomal breakages among the RA patients, treated with radioactive or nonradioactive gold, was not statistically significant. But the difference between the RA patients and the controls was significant.

Acquired chromosomal abnormalities can be seen in patients exposed to radiation, virus, and certain chemicals or in patients with various malignant diseases. The marked chromosomal abnormalities found and reported ${ }^{3}$ in our patients with lymphoma, treated with ${ }^{198} \mathrm{Au}$ for her RA, must not have been caused by the radioactivity of the ${ }^{198} \mathrm{Au}$ per se. This conclusion is based on our present finding that significant chromosomal breakages are also seen in RA patients treated with nonradioactive gold. Although it is possible that the chromosomal abnormalities found in our RA patients were associated with their primary disease rather than their treatment, we cannot make this conclusion based on our present data, since all our patients were treated with various methods. Also, it is not possible to study RA patients not treated with aspirin to rule out this possibility.

Monroe Community Hospital \&

Strong Memorial Hospital,

KONG-OO GOH

University of Rochester,

Rochester,

NY 14642, USA

\section{References}

1 Isomaki $\mathrm{H}$, Hakulinen $\mathrm{T}$, Joutsenlahti $\mathrm{U}$. Lymphoma and rheumatoid arthritis. Lancet 1979; i: 392.

2 Green J A, Dawson A A, Walker W. Systemic lupus erythematosus and lymphoma. Lancet 1978; ii: 753-6.

3 Goh K O, Jacox R F, Anderson F W. Chromosomal abnormalities: findings in a patient with lymphoma and rheumatoid arthritis treated with intra-articular gold Au-198. Arch Pathol Lab Med 1980; 104: 473-5.

4 Goh K O. Total-body irradiation and human chromosomes. IV. Cytogenetic follow-up studies 8 and $10 \frac{1}{2}$ years after total-body irradiation. Radiat Res 1975;62: 364-73.

\section{Klebsiella, ankylosing spondylitis, and statistics}

SIR, Eastmond et al. ${ }^{1}$ have followed up by post 44 ankylosing spondylitis patients. They obtained monthly a questionnaire about the clinical activity of the disease and a faecal specimen for klebsiella culture. They state that 18 patients on 19 occasions had $K$. aerogenes cultured from 